\title{
SISTEMA DE PRODUÇÃO DE MUDAS EM HÍBRIDOS INTERESPECÍFICOS ENTRE CAIAUÉ E DENDÊ
}

\author{
SYSTEM OF SEEDLING PRODUCTION IN INTERSPECIFIC HYBRIDS BETWEEN AMERICAN \\ OIL PALM AND AFRICAN OIL PALM
}

\author{
Rui Alberto Gomes Junior ${ }^{1}$ Antônio José de Abreu Pina ${ }^{2}$ Fábio de Lima Gurgel ${ }^{1}$ \\ Vinicius Ide Franzini ${ }^{1}$ Eudes de Arruda Carvalho ${ }^{3}$ Alexandre Sanz Veiga ${ }^{4}$ Leonardo Lopes Bhering ${ }^{5}$ \\ Raimundo Nonato Vieira da Cunha ${ }^{6}$
}

\section{RESUMO}

O objetivo deste trabalho foi avaliar três sistemas de produção de mudas de híbridos interespecíficos (HIE) entre caiaué e dendê, diferença entre 12 progênies de irmãos germanos do cultivar BRS Manicoré e a interação entre esses dois fatores. Os sistemas de produção avaliados foram: (i) viveiro de dois estágios com sombreamento inicial (sistema convencional); (ii) viveiro de dois estágios sem sombreamento inicial e (iii) viveiro de um estágio sem sombreamento inicial. Foram avaliadas as variáveis altura da planta, número de folhas e diâmetro do coleto aos 106, 191 e 393 dias após a semeadura. Em todas as variáveis e épocas analisadas, os fatores genótipo e ambiente foram significativos e o fator inteiração genótipo $\mathrm{x}$ ambiente não foi significativo pelo teste $\mathrm{F}$. O melhor desenvolvimento das mudas no viveiro ocorreu no sistema de produção de uma fase sem sombreamento inicial. O viveiro de duas fases com sombreamento inicial, que é atualmente o mais adotado, resultou em menor desenvolvimento das mudas.

Palavras-chave: Elaeis guineenses; Elaeis oleifera; Manicoré; viveiro.

\begin{abstract}
The objective of this study was to evaluate three systems of seedling production of interspecific hybrids of American oil palm and African oil palm (HIE), difference between 12 sib progenies of BRS Manicoré cultivar and the interaction between these two factors. The production systems were evaluated: (i) twostage nursery with the initial shading (conventional system), (ii) two-stage nursery without shading and (iii) one-stage nursery without shading. The variables evaluated were plant height, number of leaves and stem diameter at 106, 191 and 393 days after sowing. In all variables and periods analyzed, the genotype and environmental factors were significant to $F$ test, but the interaction genotype $x$ environment was not significant. The best development of seedlings in the nursery production system occurred in one-step nursery without shading. The two stages nursery with shading in pre-nursery, which is currently the most widely adopted, resulted in lower seedling development.
\end{abstract}

Keywords: Elaeis guineenses; Elaeis oleifera; Manicoré; nursery.

1 Engenheiro Agrônomo, Dr., Pesquisador, Embrapa Amazônia Oriental, Travessa Dr. Eneas Pinheiro, SN, CEP 66095-100, Belém (PA), Brasil. rui.gomes@embrapa.br / fabio.gurgel@embrapa.br / vinicius.franzini@embrapa.br

2 Engenheiro Agrônomo, Gerente Agrícola, Marborges Agroindústria S.A., Rodovia Virgilho Serrão Sacramento, Km 56, CEP 48450-000, Moju (PA), Brasil. pina@marborges.com

3 Engenheiro Agrônomo, Dr., Pesquisador, Embrapa Quarentena Vegetal, Parque Estação Biológica - PqEB, SN, CEP 70770-901, Brasília, DF, Brasil. eudes.carvalho@embrapa.br

4 Engenheiro Agrônomo, Consultor, Av Principal (Lago Azul), 75, Cond: Lago Azul;, Levilandia, CEP 67015-710, Ananindeua, PA, Brasil. asanzveiga@gmail.com

5 Engenheiro Agrônomo, Dr., Professor, Universidade Federal de Viçosa, Av. P H Rolfs, s/n - Campus Universitário, CEP 36570-000, Viçosa (MG), Brasil. leonardo.bhering@ufv.br

6 Engenheiro Agrônomo, Dr., Pesquisador, Embrapa Amazônia Ocidental, Rodovia AM-010, Km 29, CEP 69010-970, Manaus (AM), Brasil. raimundo.vieira@embrapa.br 


\section{INTRODUÇÃO}

O dendê, também, conhecido como palma-de-óleo-africana (Elaeis guineensis Jacq.) é a cultura mais produtiva entre todas as oleaginosas (BREURE, 2003). Além disto, é uma cultura perene com ciclo de 25 anos, que protege o solo, fixa grande quantidade de carbono atmosférico e se adapta bem em climas tropicais úmidos (CORLEY; TINKER, 2003). O Brasil possui mais de 30 milhões de hectares aptos para a cultura (RAMALHO FILHO et al., 2010). Uma das maiores limitações para a expansão e estabilidade da cultura no Brasil é a ocorrência do amarelecimento fatal (AF), cuja causa ainda se desconhece (BOARI, 2008).

O Caiaué, popularmente, conhecido como palma-de-óleo-americana (Elaeis oleifera (Kunth), Cortés), originário da Amazônia, é importante fonte de variabilidade para o melhoramento genético do dendê e foi incorporado em programas de melhoramento (MEUNIER, 1975; MORETZSOHN et al., 2002) inclusive da Embrapa (CUNHA et al., 2005), devido à resistência ao amarelecimento fatal (AF) e outras pragas (MOURA et al., 2013), ao lento crescimento e óleo com qualidade diferenciada, incluindo maior quantidade de ácidos graxos oleicos (BHORE et al., 2010), óleo com maiores teores de carotenoides (SUNDRAM et al., 2013) e baixa atividade de lipase (NGANDO et al., 2006), mas, seu cultivo é inviável economicamente. Entretanto, o cruzamento do caiaué com o dendê produz um híbrido interespecífico (HIE) viável em termos reprodutivos e econômicos. O HIE tem crescimento vertical lento, qualidade de óleo diferenciada e resistência ao $\mathrm{AF}$, sendo atualmente, a única alternativa para o cultivo em área de ocorrência do AF (BARCELOS et al., 2001; BOARI, 2008).

A Embrapa iniciou na década de 80 um programa de melhoramento visando ao desenvolvimento de cultivares de HIE, originando a cultivar BRS Manicoré (RNC número 26.031), primeira cultivar de HIE nacional lançada em 2010, recomendada para cultivo em área de incidência de AF (CUNHA; LOPES, 2010).

O dendê possui sistema de produção bem estabelecido, mediante décadas de estudos e adoção das melhores práticas em nível comercial. O sistema de produção adotado pelo HIE é muito recente, e atualmente, está baseado em tecnologias desenvolvidas para o dendê, sendo necessário o desenvolvimento de tecnologias próprias para o HIE.

Há dois sistemas de produção de mudas recomendados para dendê, viveiros de única fase e viveiros de duas fases, conforme descritos a seguir (BARCELOS et al., 2001):

- No viveiro de única fase, as sementes são repicadas diretamente nos sacos grandes (dimensões de $40 \mathrm{~cm}$ x $40 \mathrm{~cm} \times 0,20$ a $0,30 \mathrm{~mm}$ ), que são espaçados entre 80 e $100 \mathrm{~cm}$. Logo após a repicagem das sementes, deve ser feito um sombreamento para proteger a semente e a plântula recém-transplantada, utilizando-se dois folíolos de folha de palma, colocados em cruz sobre cada saco, os quais deverão ser mantidos por 2 a 3 meses. São produzidas mudas com idade de 10 a 16 meses.

- No viveiro de duas fases, as sementes são repicadas para sacos pequenos (dimensões de $15 \mathrm{~cm}$ x $15 \mathrm{~cm}$ x 0,05 a 0,08 mm) que são mantidos em pré-viveiro, no qual os sacos são encanteirados sob uma estrutura e é mantido sombreamento inicial com sombrite $50 \%$ ou palha, até duas semanas antes do transplantio. Ao final do pré-viveiro, com 3 a 4 meses, as mudas são transplantadas para o viveiro com sacos grandes, nos quais permanecem em período entre 8 e 12 meses.

Além destes sistemas, há estudos com tubetes que apresentaram bom desempenho em dendezeiro (CHEE et al., 1997; TEIXEIRA et al., 2006; 2009), indicando a viabilidade de inovações nesta área.

O sistema de produção de mudas mais adotado em dendê é o viveiro de duas etapas e em ambos os sistemas de produção (uma e duas etapas) é recomendado o sombreamento inicial (CORLEY; TINKER, 2003). Contudo, até o momento não foram realizados estudos para definir o melhor sistema de produção de mudas para HIE. Existe a hipótese do HIE não necessitar sombreamento inicial. Ademais, devido à grande base genética do cultivar BRS Manicoré, existe a hipótese de ocorrer variabilidade genética nas características morfológicas associadas ao desenvolvimento de mudas, assim como inteiração entre este fator genético e o fator ambiental, representado pelos diferentes sistemas de produção de mudas testados.

O objetivo do presente estudo foi avaliar o melhor sistema de produção de mudas de HIE, assim como a existência de variação no desenvolvimento das mudas entre diferentes progênies do cultivar BRS Manicoré e a inteiração entre os dois fatores. 


\section{MATERIAL E MÉTODOS}

Utilizaram-se sementes do híbrido interespecífico BRS Manicoré, oriundas do Campo Experimental do Rio Urubu (CERU) da Embrapa Amazônia Ocidental, localizado no Município de Rio Preto da Eva, Estado do Amazonas.

O experimento foi instalado na empresa Marborges Agroflorestal S.A., Município de Moju, Estado do Pará. O clima do local é do tipo equatorial, classificação climática de Köppen-Geiger Af, com pluviosidade média local (1994 a 2012) de $2.892 \mathrm{~mm}_{\text {ano }}{ }^{-1}$, e estação mais chuvosa no primeiro semestre do ano. Foi utilizado o delineamento de blocos ao acaso, em esquema fatorial 3 × 12 (3 sistemas de produção x 12 progênies de HIE), com 3 repetições e 8 plantas por parcela. Foi utilizada bordadura de uma linha ao redor do experimento, de mesmo material genético e mesmo sistema de produção.

No fator ambiente foram testados três níveis, representados pelos três sistemas de produção de mudas a seguir:

- Viveiro de duas etapas com sombreamento (VDES): este é o sistema de produção convencional de duas fases, pré-viveiro e viveiro, o mais utilizado para cultivares de dendê (BARCELOS et al. 2001). As sementes pré-germinadas foram semeadas em sacos plásticos de $15 \mathrm{~cm}$ x $15 \mathrm{~cm}$ x $0,08 \mathrm{~mm}$ em canteiros sombreados com sombrite de $50 \%$ de interceptação luminosa (pré-viveiro). Após 80 dias o sombreamento foi retirado. Com 106 dias após a semeadura, foi realizado o transplantio para sacos de $40 \mathrm{~cm}$ x $40 \mathrm{~cm}$ x 0,3 $\mathrm{mm}$ com espaçamento triangular de $1 \mathrm{~m}$ entre as embalagens, nos quais permaneceram 287 dias (viveiro).

- Viveiro de duas etapas sem sombreamento (VDEN): este é o primeiro sistema alternativo testado, que é muito similar ao convencional, com a diferença que foi excluído o sombreamento inicial. A semeadura foi realizada em sacos plásticos de $15 \mathrm{~cm}$ x $15 \mathrm{~cm}$ x $0,08 \mathrm{~mm}$ em canteiros a pleno sol, nos quais permaneceram por 106 dias (pré-viveiro), quando foram transplantados para os sacos grandes de $40 \mathrm{~cm} \mathrm{x}$ $40 \mathrm{~cm} \times 0,3 \mathrm{~mm}$ e permaneceram por mais 287 dias (viveiro).

- Viveiro de uma etapa sem sombreamento (VUEN): este é o segundo sistema alternativo testado e se assemelha ao sistema de uma fase descrito por Barcelos et al. (2001), porém, sem o sombreamento na etapa inicial. A semeadura foi executada diretamente nos sacos de $40 \mathrm{~cm}$ x $40 \mathrm{~cm}$ x $0,3 \mathrm{~mm}$, espaçados $1 \mathrm{~m}$ entre si a pleno sol, nos quais permaneceram por 393 dias.

TABELA 1: Genealogia das progênies utilizadas no estudo.

TABLE 1: Genealogy of progenies used in the study.

\begin{tabular}{lcclc}
\hline Progênie & $\begin{array}{c}\text { Cruzamento Elaeis oleifera x } \\
\text { Elaeis guineensis }\end{array}$ & $\begin{array}{c}\text { Subamostra dos } \\
\text { parentais } \\
\text { Elaeis oleifera }\end{array}$ & $\begin{array}{c}\text { Descendência } \\
\text { dos parentais } \\
\text { Elaeis } \\
\text { guineensis }\end{array}$ & $\begin{array}{c}\text { Origem dos } \\
\text { parentais Elaeis } \\
\text { guineensis }\end{array}$ \\
\hline P1 & RU 3090 D x RU 2710 P & RUC 109 & LM 12011 & LM 10 T AF \\
P2 & RU 98 D x RU 2684 P & RUC 13 & LM 13582 & LM 2 T AF \\
P3 & RU 3629 D x RU 2663 P & RUC 224 & LM 12154 & LM 2 T AF \\
P4 & RU 1493 D x RU 2734 P & RUC 13 & LM 12252 & LM 10 T AF \\
P5 & RU 1470 D x RU 2681 P & RUC 13 & LM 12582 & LM 2 T AF \\
P6 & RU 2780 D x RU 2733 P & RUC 43 & LM 12252 & LM 10 T AF \\
P7 & RU 3029 D x RU 2749 P & RUC 6 & LM 13582 & LM 2 T AF \\
P8 & RU 2980 D x RU 54 P & RUC 29 & LM 12437 & LM 2 T AF \\
P9 & RU 1500 D x RU 2729 P & RUC 16 & LM 13751 & LM 2 T AF \\
P10 & RU 1496 D x RU 40 P & RUC 13 & LM 12364 & LM 10 T AF \\
P11 & RU 73 D x RU 49 P & RUC 17 & LM 12154 & LM 2T AF \\
P12 & RU 87 D x RU 2687 P & RUC 100 & LM 13582 & LM 2T AF \\
\hline
\end{tabular}


O fator genótipo foi constituído por 12 níveis, representados por 12 progênies F1 de HIE (Tabela 1) obtidas utilizando como genitores femininos 12 plantas de caiaué de 9 subamostras (identificadas pelo código RUC), todas da origem Manicoré, e como genitores masculinos 12 plantas pisíferas de 5 descendências da origem LM 2 T e 3 descendências da origem LM 10 T.

A semeadura foi realizada em 08/02/2011 (início da estação chuvosa) e o transplantio do viveiro para o pré-viveiro (apenas viveiro de duas etapas sombreado e viveiro de duas etapas sem sombreamento) foi executado em 25/05/2011. O manejo adotado para as plantas durante a condução do experimento, incluindo o substrato, adubação, irrigação e controle de plantas daninhas, pragas e doenças está descrito por Pina (2010).

O desenvolvimento das mudas foi avaliado segundo a mensuração do diâmetro do coleto (DC - cm), da altura da planta desde a base até o final da nervura central ou raquis da folha mais alta (AP $\mathrm{cm}$ ) e do número de folhas (NF - unidade). Estas avaliações foram realizadas em três épocas diferentes, sendo a primeira avaliação (E1) em 25/05/2011 com 106 dias após a semeadura (das), a segunda avaliação em 18/08/2011 com 191 das e a terceira avaliação em 07/03/2012 com 393 das. A primeira avaliação foi realizada na mesma data do transplantio. A última avaliação foi realizada na etapa final do viveiro, na véspera do plantio. A avaliação intermediária foi executada para verificar a linearidade do desenvolvimento das mudas.

O experimento foi analisado seguindo o esquema fatorial $12 \times 3$ (progênies $\mathrm{x}$ ambiente), delineamento em blocos ao acaso com três repetições. A análise dos dados foi realizada no programa estatístico Genes (CRUZ, 2006), baseado em modelo Yijk $=\mathrm{m}+\mathrm{Bk}+\mathrm{Gi}+\mathrm{Aj}+\mathrm{GAij}+$ Eijk, em que $\mathrm{m}$ representa a média da população, Bk o efeito do bloco k, Gi o efeito da progênie i, Aj o efeito do sistema de produção (ambiente) j, GAij o efeito da interação entre a progênie i e o sistema de produção j e Eijk o efeito do erro experimental. Neste modelo, o fator sistema de produção foi considerado fixo e os efeitos de progênie, bloco e erro experimental como aleatórios.

Foi realizada análise de variância (ANAVA) e teste de comparação de médias de Tukey (Tabela 2) para os sistemas de produção nos diferentes períodos avaliados, e análise de regressão para verificar o comportamento das variáveis (altura da planta, diâmetro do coleto e número de folhas) ao longo do tempo (dias após a semeadura) nos três sistemas de produção testados.

TABELA 2: Esquema da análise de variância.

TABLE 2: Scheme of analysis of variance.

\begin{tabular}{|c|c|c|c|c|}
\hline F. V. ${ }^{1}$ & $\mathrm{GL}^{2}$ & $\mathrm{QM}^{3}$ & $\mathrm{EQM}^{4}$ & TESTE F \\
\hline Bloco & $b-1=2$ & $\mathrm{QM}_{\mathrm{b}}$ & $\sigma^{2}+$ ga. $\sigma_{b}^{2}$ & $\mathrm{QM}_{\mathrm{b}} / \mathrm{QM}_{\mathrm{r}}$ \\
\hline Ambiente (A) & $a-1=2$ & $\mathrm{QM}_{\mathrm{a}}$ & $\sigma^{2}+\mathrm{ra} /(\mathrm{a}-1) \cdot \sigma_{\mathrm{a}}^{2}+\operatorname{gr}_{\mathrm{a}}^{2}$ & $\mathrm{QM}_{\mathrm{a}} / \mathrm{QM}_{\mathrm{ga}}$ \\
\hline Genótipo $(\mathrm{G})$ & $\mathrm{g}-1=11$ & $\mathrm{QM}_{\mathrm{g}}{ }^{\mathrm{C}}$ & $\sigma^{2}+\operatorname{ar} . \sigma_{g}^{2}$ & $\mathrm{QM}_{\mathrm{g}} / \mathrm{QM}_{\mathrm{r}}$ \\
\hline $\mathrm{G} \times \mathrm{A}$ & $(a-1) \cdot(g-1)=22$ & $\mathrm{QM}_{\mathrm{ga}}^{\mathrm{g}}$ & $\sigma^{2}+$ rl. $\sigma_{\mathrm{ga}}^{2}$ & $\mathrm{QM}_{\mathrm{ga}}^{\mathrm{g}} / \mathrm{QM}_{\mathrm{r}}$ \\
\hline Resíduo & $($ g.a-1)(b-1) $=70$ & $\mathrm{QM}_{\mathrm{e}}$ & $\sigma^{2}$ & \\
\hline Total & b.g.a-1 = 107 & & & \\
\hline
\end{tabular}

Em que: ${ }^{1}$ fonte de variação; ${ }^{2}$ graus de liberdade; ${ }^{3}$ quadrado médio; ${ }^{4}$ esperança do quadrado médio.

\section{RESULTADOS E DISCUSSÃO}

Os valores médios de altura da planta foram de 35,6, 51,9 e 127,2 cm aos 106, 191 e 393 dias após a semeadura, respectivamente. O diâmetro do coleto apresentou valores médios de 0,89, 2,4 e 8,6 cm aos 106, 191 e 393 dias após a semeadura, respectivamente. O número de folhas foi de 3,9, 8,8 e 15,5 aos 106, 191 e 393 dias após a semeadura, respectivamente (Tabela 3). Resultados similares foram obtidos por Teixeira et al. (2009) estudando mudas de dendê, obtendo no tratamento-testemunha (similar ao viveiro de duas etapas sombreado) valores de diâmetro do coleto igual a $6,51 \mathrm{~cm}$ e altura da planta igual a $91,6 \mathrm{~cm}$ aos 10 meses 
de idade, enquanto que aos 16 meses de idade, o valor de diâmetro do coleto foi de 9,6 cm e de altura da planta foi de $177,6 \mathrm{~cm}$.

TABELA 3: Média geral, amplitude e coeficiente de variação das variáveis.

TABLE 3: General average, range and coefficient of variation of the variables.

\begin{tabular}{lccccccccc}
\hline & \multicolumn{3}{c}{ Diâmetro do coleto $(\mathrm{cm})$} & \multicolumn{3}{c}{ Número de folhas } & \multicolumn{2}{c}{ Altura da planta } \\
\cline { 2 - 9 } & 106 das & 191 das & 393 das & 106 das & 191 das & 393 das & 106 das & 191 das & 393 das \\
\hline Média & 0,89 & 2,4 & 8,6 & 4,7 & 10,9 & 19,8 & 35,6 & 51,9 & 127,2 \\
Mínimo & 0,55 & 1,5 & 6,6 & 3,9 & 8,8 & 15,5 & 21,7 & 41,4 & 103,7 \\
Máximo & 1,23 & 4,2 & 10,6 & 6,0 & 13,0 & 26,4 & 46,1 & 62,9 & 154,4 \\
CV (\%) & 9,6 & 17,0 & 5,9 & 5,0 & 5,8 & 7,5 & 6,5 & 6,6 & 5,9 \\
\hline
\end{tabular}

Em que: das $=$ dias após a semeadura.

O experimento teve boa precisão experimental uma vez que as variáveis apresentaram valores de CV baixos comparados ao que é visto na literatura para a cultura do dendê e as variáveis avaliadas. A variável diâmetro do coleto na E2 apresentou o maior CV no valor de $17 \%$, enquanto que as demais variáveis e épocas testadas apresentaram CV abaixo de 10\% (Tabela 3). Teixeira et al. (2009) apresentaram valores de CV de 4 a 12\% nas variáveis diâmetro do coleto e altura da planta. Tendo em vista os coeficientes de variação obtidos comumente nos ensaios agrícolas de campo, podendo-se considerá-los baixos, quando inferiores a $10 \%$, médios, quando de 10 a $20 \%$, altos, quando de 20 a $30 \%$, muito altos, quando superiores a 30\% (GOMES, 1987).

Todas as nove variáveis (três características vegetativas $\mathrm{x}$ três épocas de avaliação) estudadas apresentaram comportamento similar em relação ao teste F (ANAVA) (Tabela 4).

TABELA 4: Quadrado Médio dos fatores progênie, sistema de produção e inteiração sistema de produção x progênie nas três variáveis e três épocas de avaliação.

TABLE 4: Mean Square of progeny factors, production system and complementary nature production system by progeny in three variables and three evaluation periods.

\begin{tabular}{lccccccccc}
\hline \multirow{2}{*}{$\begin{array}{l}\text { Fonte de } \\
\text { variação }\end{array}$} & \multicolumn{3}{c}{ Diâmetro do coleto } & \multicolumn{3}{c}{ Número de folhas } & \multicolumn{3}{c}{ Altura da planta } \\
\cline { 2 - 9 } & 106 das & 191 das & 393 das & 106 das & 191 das & 393 das & 106 das & 191 das & 393 das \\
\hline Blocos & 0,01 & 0,1 & 0,1 & 0,2 & 1,2 & 1,2 & 0,6 & 20,8 & 28,6 \\
Progênie & $0,04^{* *}$ & $0,6^{* *}$ & $0,7^{* *}$ & $0,4^{* *}$ & $1,4^{* *}$ & $7,7^{* *}$ & $42,3^{* *}$ & $44,3^{* *}$ & $403,5^{* *}$ \\
Sistema & $0,86^{* *}$ & $5,4^{* *}$ & $11,0^{* *}$ & $12,2^{* *}$ & $5,3^{* *}$ & $13,5^{* *}$ & $865,1^{* *}$ & $554,0^{* *}$ & $811,2^{* *}$ \\
P x S & $0,01^{\text {ns }}$ & $0,1^{\text {ns }}$ & $0,4^{\text {ns }}$ & $0,1^{\text {ns }}$ & $0,4^{\text {ns }}$ & $0,9^{\text {ns }}$ & $5,8^{\text {ns }}$ & $14,7^{\text {ns }}$ & $40,1^{\text {ns }}$ \\
Resíduo & 0,01 & 0,2 & 0,3 & 0,1 & 0,4 & 2,2 & 5,3 & 11,8 & 56,6 \\
\hline
\end{tabular}

Em que: ${ }^{* *}=$ significativo a $1 \%$ de probabilidade segundo teste $\mathrm{F} ;{ }^{\text {ns }}=$ não significativo; das $=$ dias após a semeadura.

O fator progênie apresentou diferença significativa ao nível de $1 \%$ de probabilidade, indicando diferença no desenvolvimento das mudas em função do material genético. Cuesta et al. (2008) estudando o desenvolvimento vegetativo no viveiro de diferentes híbridos comerciais de dendê-africano tipo tenera observaram diferenças significativas entre os materiais no diâmetro do coleto e altura da planta, indicando variabilidade dentro da espécie africana. Em outro estudo de campo, conduzido no Município de Rio Preto da Eva - AM, em que se avaliou a produção de cachos de 59 progênies F1 de caiaué com dendê de diversas origens, observou-se que as progênies avaliadas apresentaram alta variabilidade genética quanto à produção de cachos (LOPES et al., 2012). 
Chia et al. (2012) observaram também diferença na frequência (variação de 20,0\% a 100,0\%) de plantas com inflorescências ginandromorfas (anomalias nas inflorescências masculinas) em 11 cruzamentos de caiaué com dendê pisífera, demonstrando a variabilidade genética em diferentes características no híbrido interespecífico. Diversos estudos foram realizados em dendezeiro para seleção precoce, e o único que teve elevado sucesso foi com resistência a fusarium, enquanto que correlações de variáveis no viveiro com produção em campo não apresentaram bons resultados (CORLEI; TINKER, 2003). Por isso, neste estudo, não foi feita a comparação de médias entre as diferentes progênies testadas, mas se entende que devido à variabilidade existente entre as progênies do BRS Manicoré, foi importante fazer a sistematização dos materiais genéticos a fim de ter estimativas representativas dos efeitos dos sistemas de produção sobre o desenvolvimento das plantas.

$\mathrm{O}$ fator sistema de produção $(\mathrm{S})$ que possui três níveis diferentes também foi significativo a $1 \%$ de probabilidade, indicando a existência de ao menos um contraste entre os níveis testados. A identificação de sistemas de produção mais eficientes que o convencional é a principal hipótese do trabalho, por isso foram feitos teste de comparação de médias e análise de regressão do desenvolvimento ao longo do tempo. $\mathrm{O}$ fator interação genótipos $\mathrm{x}$ ambientes não foi significativo em todas as variáveis. Em termos práticos é um resultado interessante, pois indica que não há comportamento diferencial dos genótipos em resposta a diferentes ambientes.

A variável altura da planta (Tabela 5) na primeira mensuração demonstrou que o sistema de produção de viveiro de uma etapa sem sombreamento teve valor inferior aos outros dois sistemas testados, na primeira época de avaliação com 106 dias após a semeadura.

TABELA 5: Comparação entre médias de três sistemas de produção de mudas.

TABLE 5: Comparison between the means of three production systems of seedlings.

\begin{tabular}{lcccc}
\hline \multicolumn{1}{c}{ Variável } & Época & $\begin{array}{c}\text { Duas etapas com } \\
\text { sombreamento }\end{array}$ & $\begin{array}{c}\text { Duas etapas sem } \\
\text { sombreamento }\end{array}$ & $\begin{array}{c}\text { Uma etapa sem } \\
\text { sombreamento }\end{array}$ \\
\hline Altura de planta $(\mathrm{cm})$ & 106 das & $38,7^{\mathrm{a}}$ & $38,3^{\mathrm{a}}$ & $30,0^{\mathrm{b}}$ \\
Altura de planta (cm) & 191 das & $48,7^{\mathrm{b}}$ & $50,8^{\mathrm{b}}$ & $56,3^{\mathrm{a}}$ \\
Altura de planta (cm) & 393 das & $122,7^{\mathrm{a}}$ & $126,6^{\mathrm{a}}$ & $132,2^{\mathrm{a}}$ \\
Diâmetro do coleto (cm) & 106 das & $0,7^{\mathrm{b}}$ & $1,0^{\mathrm{a}}$ & $1,0^{\mathrm{a}}$ \\
Diâmetro do coleto (cm) & 191 das & $2,2^{\mathrm{a}}$ & $2,3^{\mathrm{a}}$ & $2,9^{\mathrm{a}}$ \\
Diâmetro do coleto (cm) & 393 das & $8,2^{\mathrm{b}}$ & $8,4^{\mathrm{b}}$ & $9,2^{\mathrm{a}}$ \\
Número de folhas & 106 das & $4,1^{\mathrm{b}}$ & $5,2^{\mathrm{a}}$ & $4,9^{\mathrm{a}}$ \\
Número de folhas & 191 das & $10,5^{\mathrm{a}}$ & $11,1^{\mathrm{a}}$ & $11,3^{\mathrm{a}}$ \\
Número de folhas & 393 das & $19,2^{\mathrm{a}}$ & $20,0^{\mathrm{a}}$ & $20,4^{\mathrm{a}}$ \\
\hline
\end{tabular}

Em que: Médias seguidas com mesma letra na linha não diferem significativamente entre si, segundo teste de Tukey a $5 \%$ de probabilidade; das $=$ dias após a semeadura .

O maior crescimento em altura pode ser indicativo de melhores tratos culturais (irrigação, monda, adubação, etc.) em mudas pequenas quando em pré-viveiro, pois estas operações são facilitadas pela proximidade entre as mudas no canteiro. Por outro lado, o maior crescimento inicial das mudas em sistemas de produção com pré-viveiro (viveiro de duas etapas com sombreamento e viveiro de duas etapas sem sombreamento) podem indicar estiolamento das mudas. Na segunda época avaliada (191 dias após a semeadura), o sistema viveiro de uma etapa sem sombreamento foi o que apresentou maior altura de muda. Na terceira época avaliada (393 dias após a semeadura), não houve diferença significativa na variável altura da planta entre os três sistemas avaliados, indicando que as mudas se recuperaram das variações impostas pelos diferentes ambientes, que foram percebidas significativamente nos períodos anteriores.

Segundo a análise de regressão (Figura 1), o viveiro de uma etapa sem sombreamento foi o que teve menor valor inicial, mas devido à maior inclinação da reta $\left(Y=-9,89+0,359 \mathrm{X} ; \mathrm{R}^{2} 98 \%\right)$ foi o sistema 


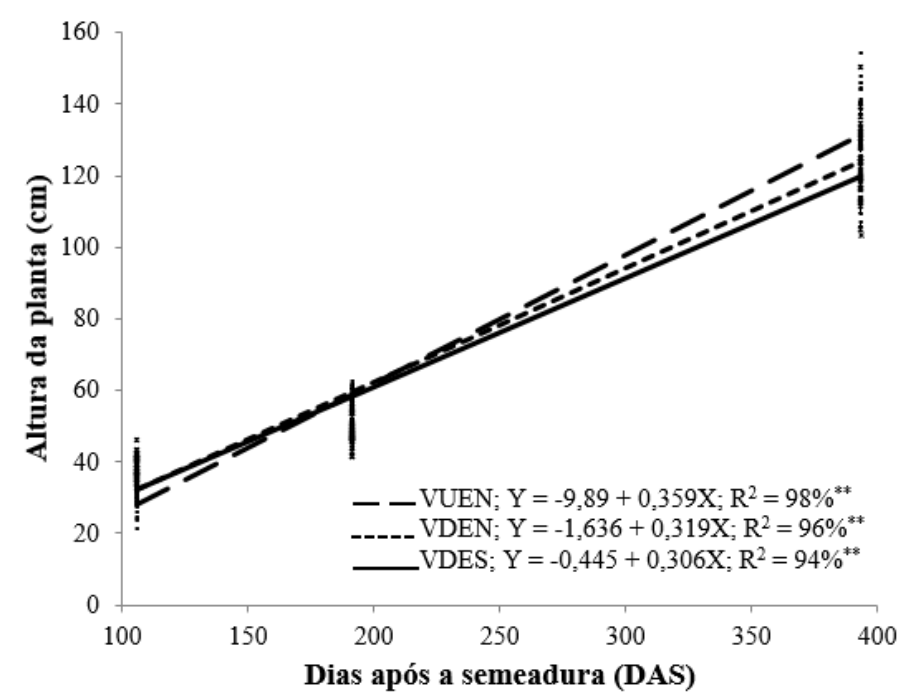

**Regressão linear significativa a $1 \%$ de probabilidade, segundo teste F. VDES: viveiro de duas etapas com sombreamento inicial. VDEN: viveiro de duas etapas sem sombreamento. VUEN: viveiro de uma etapa sem sombreamento.

FIGURA 1: Associação entre a idade e a altura da planta em três sistemas de produção.

FIGURE 1. Association between age and height of the plant in three production systems.

com maior desempenho nesta característica no período final. Nesta análise, a segunda colocação foi para o viveiro de duas etapas sem sombreamento $\left(\mathrm{Y}=-1,636+0,319 \mathrm{X} ; \mathrm{R}^{2} 96 \%\right)$, e a última para o viveiro de duas etapas com sombreamento inicial $\left(\mathrm{Y}=-0,444+0,306 \mathrm{X} ; \mathrm{R}^{2} 94 \%\right)$, sendo que o último é o sistema mais adotado para a produção de mudas de dendê-africano.

A análise de regressão demonstrou que nos três sistemas houve aumento linear do diâmetro do coleto ao longo do tempo (Figura 2).

$\mathrm{O}$ viveiro de uma etapa sem sombreamento teve o maior coeficiente de inclinação ( $\mathrm{Y}=-2,347$ $+0,029 \mathrm{X} ; \mathrm{R}^{2}$ 98\%) culminando com o maior valor ao final do período. $\mathrm{O}$ viveiro de duas etapas sem

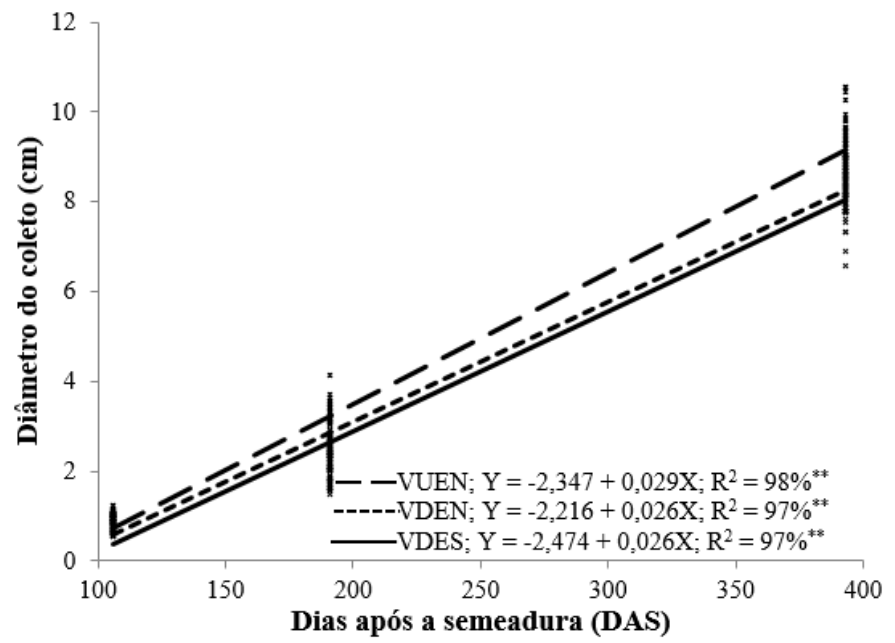

**Regressão linear significativa a $1 \%$ de probabilidade, segundo teste F. VDES: viveiro de duas etapas com sombreamento inicial. VDEN: viveiro de duas etapas sem sombreamento. VUEN: viveiro de uma etapa sem sombreamento.

FIGURA 2: Associação entre a idade e o diâmetro do coleto em três sistemas de produção.

FIGURE 2: Association between age and stem diameter of the plant in three production systems. 
sombreamento ficou com a segunda colocação ( $\mathrm{Y}=-2,216+0,026 \mathrm{X} ; \mathrm{R}^{2}$ 97\%). O viveiro de duas etapas com sombreamento inicial foi o que teve menor desenvolvimento do diâmetro do coleto, desde a primeira até a última época avaliada ( $\mathrm{Y}=\mathrm{Y}=-2,474+0,026 \mathrm{X} ; \mathrm{R}^{2}$ 97\%). O padrão de desenvolvimento ao longo do tempo das variáveis testadas neste estudo ajustados à regressão linear também foi relatado por Cuesta et al. (2008) nas variáveis altura da planta e diâmetro do coleto, em mudas de diferentes híbridos comerciais de dendê-africano.

Na primeira época avaliada (106 dias após a semeadura), o diâmetro do coleto no ambiente viveiro de duas etapas com sombreamento inicial foi significativamente inferior aos outros dois ambientes, evidenciando menor desenvolvimento das mudas no período inicial (Tabela 5). Na segunda época (191 dias após a semeadura), o valor do diâmetro do coleto não diferiu significativamente entre os três sistemas de produção. Na terceira época (393 dias após a semeadura), o sistema viveiro de uma etapa sem sombreamento apresentou o maior diâmetro do coleto, enquanto o viveiro de duas etapas sem sombreamento e o viveiro de duas etapas sombreado não diferiram estatisticamente entre si.

A emissão de folhas é associada ao bom desenvolvimento de mudas e plantas, indicando aporte adequado de água, luz e nutrientes. No presente estudo, o número de folhas (Tabela 5) foi significativamente menor no viveiro de duas etapas com sombreamento inicial do que nos outros dois sistemas na primeira época (106 dias após a semeadura). Na segunda e terceira épocas (191 e 393 dias após a semeadura), o número de folhas não diferiu significativamente entre os três sistemas de produção. Esta variável foi a que apresentou menor diferença entre os três sistemas de produção.

$\mathrm{Na}$ análise de regressão (Figura 3) o viveiro de uma etapa sem sombreamento apresentou o melhor desempenho na variável número de folhas, destacado na última época avaliada, devido ao maior coeficiente angular $\left(\mathrm{Y}=0,166+0,052 \mathrm{X} ; \mathrm{R}^{2} 95 \%\right)$. $\mathrm{O}$ viveiro de duas etapas sem sombreamento $(\mathrm{Y}=0,579+0,05 \mathrm{X}$; $\mathrm{R}^{2} 96 \%$ ) foi o segundo colocado. $\mathrm{O}$ último colocado foi o viveiro de duas etapas sombreado $(\mathrm{Y}=-0,388+$ $\left.0,05 \mathrm{X} ; \mathrm{R}^{2} 95 \%\right)$.

Jinks e Mason (1998) verificaram que o aumento na densidade na produção de mudas reduziu a biomassa de raízes e da parte aérea em diversas espécies. Timmis e Tanaka (1976) afirmam que a diminuição da produção de biomassa em densidades maiores é causada por redução considerável na interceptação da radiação fotossinteticamente ativa que pode ser até dez vezes menor em maiores densidades. Chinchilla, Umaña e Richardson (1990) estudando viveiros de dendê de idade avançada (18 meses) constataram que

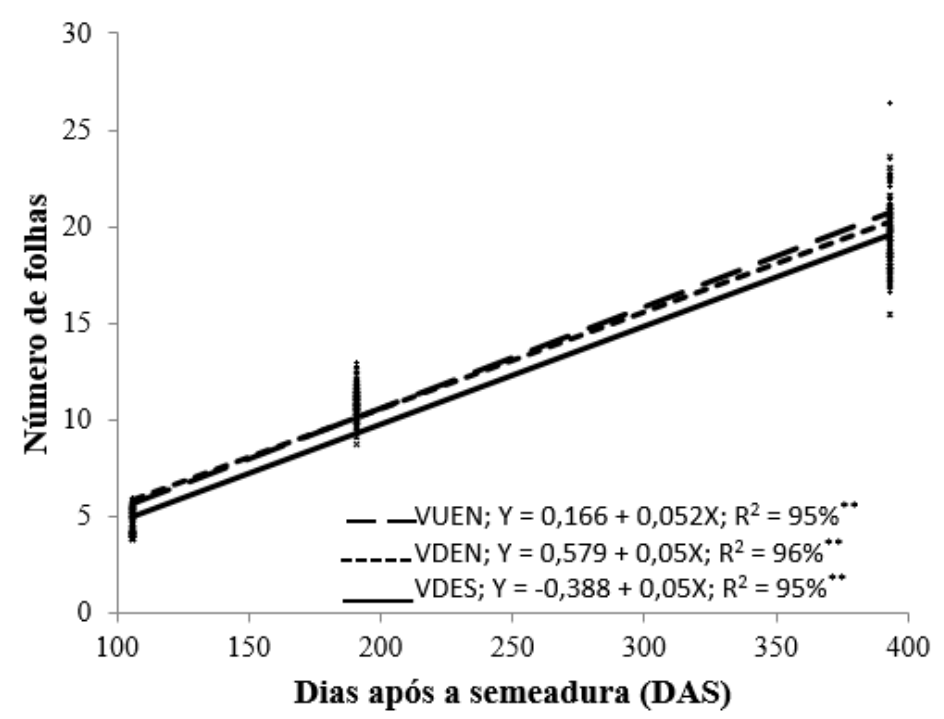

**Regressão linear significativa a $1 \%$ de probabilidade, segundo teste F. VDES: viveiro de duas etapas com sombreamento inicial. VDEN: viveiro de duas etapas sem sombreamento. VUEN: viveiro de uma etapa sem sombreamento.

FIGURA 3: Associação entre a idade e o número de folhas em três sistemas de produção.

FIGURE 3: Association between age and number of leaves of the plant in three production systems. 
o espaçamento foi o principal fator sobre o desenvolvimento das plantas, devido ao estiolamento em menores espaçamentos, superando outros fatores como adubação e tamanho do saco. O estiolamento no período juvenil prejudica o desenvolvimento das mudas e no período adulto causa efeitos mais graves, principalmente a queda drástica na produção de cachos (RAO et al., 1990). Contudo, nos diferentes sistemas de produção de mudas de dendê é recomendado o sombreamento inicial para evitar desidratação das mudas (CORLEI; TINKER, 2003; BARCELOS et al., 2001; PINA, 2010; GOMES JUNIOR, 2010; RANKINE; FAIRHURST, 2008). O estudo atual mostra que o HIE, se comportou melhor na ausência de sombreamento, podendo receber recomendação diferenciada do dendê-africano. É importante ressaltar que a semeadura foi realizada em fevereiro, início da estação chuvosa, época de maior quantidade de água e menor insolação. Os resultados deste estudo não sustentam recomendação para semeadura no segundo semestre do ano. Apesar de a irrigação diária no viveiro, a maior presença de radiação na estação seca pode causar prejuízo ao desenvolvimento das mudas. Ademais, no período seco, fatais quebras no sistema de irrigação não seriam compensadas adequadamente pela pluviosidade.

Outro fator que teve impacto sobre o desenvolvimento foi o transplantio das mudas, pois o viveiro de uma etapa não sombreado foi o de melhor desempenho entre os três sistemas testados. Barcelos et al. (2001b) e Rankine e Fairhurst (2008) citam a vantagem de não haver estresse no transplantio em viveiros de um estágio. Corley e Tinker (2003) relatam que viveiros de uma etapa têm como vantagem a redução de cerca de dois meses para a formação da muda. Considerando os resultados do presente estudo sobre o desenvolvimento de mudas e as épocas ideais para semeadura e plantio das mudas, o viveiro de uma etapa não sombreado teve melhores resultados e pode ser recomendado para a produção de mudas jovens com até 13 meses de idade.

\section{CONCLUSÕES}

O viveiro de uma etapa sem sombreamento foi o melhor sistema para o desenvolvimento de mudas de até 13 meses de idade de HIE cultivar BRS Manicoré. Em segundo lugar foi o viveiro de duas etapas sem sombreamento. Apesar de ser referência para o dendê, o viveiro de duas etapas com sombreamento inicial foi o que teve o pior desempenho.

Há diferença significativa no desenvolvimento de mudas entre diferentes progênies do cultivar BRS Manicoré.

A ausência de interação genótipo $\mathrm{x}$ ambiente neste experimento indica que a seleção do melhor sistema de produção atende a todas as progênies testadas.

\section{AGRADECIMENTOS}

A Embrapa e ao Grupo MARBORGES pela viabilidade do estudo.

\section{REFERÊNCIAS}

BARCELOS, E. et al. Produção de mudas de dendê na Amazônia. Manaus: Embrapa Amazônia Ocidental, 2001. 11 p. (Embrapa Amazônia Oriental. Circular Técnica, 8).

BARCELOS, E.; CUNHA, R. N. V.; NOUY, B. Recursos genéticos de dendê (Elaeis guineensis Jacq. e Elaeis oleifera (Kunth), Cortés) disponíveis na Embrapa e sua utilização. In: MÜLLER, A. A.; FURLAN JÚNIOR, J. Agronegócio do dendê: uma alternativa social, econômica e ambiental para o desenvolvimento sustentável da Amazônia. Belém: Embrapa Amazônia Oriental, 2001. p. 131-143.

BHORE, S. J.; KASSIM, A.; SHAH, F. H. Insights from the GC content analysis of 76 genome survey sequences (GSS) from Elaeis oleifera. Bioinformation, Tamil Nadu, v. 5, n. 4, p. 141- 145, 2010.

BOARI, A. J. Estudos realizados sobre o Amarelecimento Fatal do Dendê (Elaeis guineensis Jack) no Brasil. Belém: Embrapa Amazônia Oriental, 2008. 62 p. (Documento, 248).

BREURE, K. The search for yield in oil palm: basic principles. In: FAIRHURST, T.; HARDTER, R. (Eds.). The oil palm. Management for large and sustainable yields. Penang: Potash \& Phosphate Institute; Potash Institute of Canada and International Potash Institute, 2003. p. 59-98. 
CHEE, K. H.; CHIU, S. B.; CHAN, S. M. Pre-nursery seedlings grown on pot trays. The Planter, Kuala Lumpur, v. 73, n. 855, p. 295-299, 1997.

CHIA, G. S. et al. Gene sh e ginandromorfia em inflorescências masculinas de híbridos F1 entre o caiaué e o dendê. Revista de Ciências Agrárias, Belém, v. 55, p. 212-219, 2012.

CHINCHILLA, C.; UMAÑA, C. H.; RICHARDSON, D. L. Material de desarrollo avanzado en viveros de palma aceitera (Elaeis guineensis Jacq.). I. Espaciamiento y volumen de bolsa. Turrialba, San José, v. 40, n. 4, p. 428-439, 1990.

CORLEY, R. H. V.; TINKER, P. B. The Oil Palm. Oxford: Blackwell Science, 2003. 608 p.

CRUZ, C. D. Programa GENES: biometria. Viçosa: UFV, 2006. 452 p.

CUESTA, R. R. et al. Nursery growth and development of comercial oil palm (Elaeis guineensis Jacq.) in Tumaco, Colômbia. Revista Corpoica, Bogotá, v. 9, n. 1, p. 12, 2008.

CUNHA, R. N. V. et al. Produção de híbridos interespecíficos entre o Caiaué (Elaeis oleifera Kunt, Cortez) e o dendê (Elaeis guineensis Jacq.). In: CONGRESSO BRASILEIRO DE PLANTAS OLEAGINOSAS, ÓLEOS, GORDURAS E BIODIESEL, 2., 2005, Varginha. Anais... Lavras: UFLA, 2005.

CUNHA, R. N. V.; LOPES, R. BRS Manicoré: Híbrido interespecífico entre Caiaué e o Dendê Africano recomendado para áreas de incidência do amarelecimento-fatal. Manaus: Embrapa Amazônia Ocidental, 2010. 3 p. (Comunicado Técnico, 85).

GOMES, F. P. Curso de estatística experimental. 13 ed. Piracicaba: Esalq, 1987. 466 p.

GOMES JUNIOR, R. A. Bases técnicas para a cultura da dendê integrado na unidade produtiva da agricultura familiar. Belém: Embrapa Amazônia Oriental, 2010. 190 p.

JINKS, R.; MASON, B. Effects of seedling density on the growth of Corsican pine (Pinus nigra var. maritime Melv.), Scots pine (Pinus sylvestris L.) and Douglas-fir (Pseudotsuga menziesii Franco) in containers. Annals of Forest Science, Champenoux, v. 55, p. 407-423, 1998.

LOPES, R.; CUNHA, R. N. V.; RESENDE, M. D. V. Produção de cachos e parâmetros genéticos de híbridos de caiaué com dendê. Pesquisa Agropecuária Brasileira, Brasília, v. 47, p. 1496-1503, 2012.

MEUNIER, J. L. E. Palmier à huile: américain Elaeis melanococca. Oléagineux, Paris, v. 30, p. 51-61, 1975.

MORETZSOHN, M. C. et al. Genetic diversity of Brazilian oil palm (Elaeis oleifera HBK) germoplasm collected in the Amazon Forest. Euphytica, Wageningen, v. 124, n. 1, p. 35-45, 2002.

MOURA, J. I. L. et al. Preferência do bicudo-das-palmeiras por dendezeiro, caiaué e por seu híbrido interespecífico. Pesquisa Agropecuária Brasileira, Brasília, v. 48, n. 4, p. 454-456, 2013.

NGANDO, E.G. et al. Assaying lipase activity from oil palm fruit (Elaeis guineensis Jacq.) mesocarp. Plant Physiology and Biochemistry, Paris, v. 44, p. 611-617, 2006.

PINA, A. J. A. Produção sustentável para a cultura da dendê na Amazônia: experiência da Marborges Agroindústria S.A. em Moju (Estado do Pará). In: RAMALHO FILHO, A. et al. Zoneamento Agroecológico, Produção e Manejo para a Cultura da Dendê na Amazônia. Rio de Janeiro: Embrapa Solos, 2010. p. 189-204.

RAMALHO FILHO, A. et al. Zoneamento agroecológico para a cultura da dendê nas áreas desmatadas da Amazônia Legal. In: et al. Zoneamento agroecológico, produção e manejo para a cultura da dendê na Amazônia. Rio de Janeiro: Embrapa Solos, 2010. p. 57-68 .

RANKINE, I.; FAIRHURST, T. Palm Series: Nursery. Penang: International Plant Nutrition Institute (IPNI); Yogyakarta: PT Agrisoft Systems Indonesia, 2008. v. 1, 109 p.

1. RAO, V. et al. Density effects in the oil palm. In: INTERNATIONAL WORKSHOP ON YIELD POTENTIAL IN THE OIL PALM, 1990, Phuket. Proceedings... 1990.

SUNDRAM, K.; SAMBANTHAMURTHI, R.; TAN, Y-A. Palm fruit chemistry and nutrition. Asia Pacific Journal of Clinical Nutrition, London, v. 12, n. 3, p. 355-362, 2013.

TEIXEIRA, P. C. et al. Crescimento de mudas de dendezeiro (Elaeis guineensis Jacq.) produzidas em tubetes e em sacolas plásticas durante a fase de pré-viveiro. In: FERTBIO, 2006, Bonito. Anais... Bonito: Embrapa Agropecuária Oeste, 2006. 1CD-ROM.

TEIXEIRA, P. C. et al. Influência da disposição dos tubetes e da aplicação de fertilizantes de liberação lenta, durante o pré-viveiro, no crescimento de mudas de dendê (Elaeis guineensis Jacq.) Ciência Florestal, Santa Maria, v. 19, n. 2, p. 157-168, 2009. 
TIMMIS, R.; TANAKA, Y. Effects of container density and plant water stress on growth and cold hardiness of Douglas-fir seedlings, Forest Science, Bethesda, v. 22, n. 2, p. 167-172, 1976. 